\section{The complex relationship between weight and sleep apnoea}

\author{
Sanjay R Patel
}

Obesity has long been recognised as the most important reversible risk factor for obstructive sleep apnoea (OSA). Analyses from the Wisconsin Sleep Cohort Study suggest that $41 \%$ of adult OSA cases, including $58 \%$ of moderate-to-severe cases, are attributable to overweight or obesity. ${ }^{1}$ As such, weight loss has long been recommended as an ancillary treatment for OSA. Longitudinal analyses from the Sleep Heart Health Study support the notion that weight loss is associated with improvements in OSA severity. $^{2}$ However, the beneficial impact of weight loss was much less than the adverse effect of the same amount of weight gain in that study suggesting that the relationship between obesity and OSA is more complex than can be explained by an acute (and reversible) unidirectional causal model.

Given evidence that short sleep durations and poor quality sleep predict an increased rate of weight gain, ${ }^{3} 4$ many have postulated that OSA may itself predispose to obesity. Retrospective data indicate that those with recently diagnosed OSA are more likely to have had recent weight gain. ${ }^{5}$ These findings have been used to support the contention that OSA causes weight gain but of course, this may simply reflect the impact of weight gain on OSA risk. An association between OSA and elevated leptin levels, which fall with CPAP therapy, suggests that an effect of OSA on weight gain may be mediated by leptin resistance whereby improvements in leptin resistance with OSA treatment would produce weight loss. ${ }^{6}$ Uncontrolled studies have reported that initiation of CPAP therapy is associated with induction of mild weight loss. ${ }^{7}$ However, given that most patients are educated on the association between obesity and OSA at the time of CPAP prescription, whether these observations were due to CPAP itself or due to concomitant weight loss attempts by the patient was never clear. Nevertheless, many clinicians have continued to counsel

Correspondence to Dr Sanjay R Patel, Division of Sleep and Circadian Disorders, Brigham and Women's Hospital, Harvard Medical School, 221 Longwood Avenue, Room 225-C, Boston, MA 02115, USA; spatel@partners.org their patients that use of CPAP might help them in losing weight.

More recently, analyses from the Apnea Positive Pressure Long-term Efficacy Study (APPLES) have lain to rest the myth that CPAP causes weight loss. In that 6-month trial, patients randomised to CPAP gained weight, whereas those randomised to sham lost weight (presumably due to concomitant weight loss attempts). The difference between groups $(\sim 1.0 \mathrm{~kg})$ was small but statistically significant. ${ }^{8}$ Furthermore, a dose-response relationship was identified, whereby increased CPAP adherence was associated with greater weight gain. In this issue of Thorax, Drager et $a l^{9}$ have now confirmed the APPLES findings by conducting a meta-analysis including 25 well-designed randomised controlled trials (RCTs) enrolling over 3000 patients with OSA. Across studies ranging from 1 to 48 months in duration, they report that CPAP is associated with a $0.5 \mathrm{~kg}$ weight gain compared with control therapy. The authors are to be congratulated in making use of existing data from a large number of prior RCTs. Almost every OSA trial measures weight at baseline and follow-up, so the data were readily available even if not previously reported. Given that weight was not a key outcome in any of these trials, the likelihood of publication or other selection biases in the identification of data for this meta-analysis is low. Although the meta-regression analyses did not reveal any sources of heterogeneity in the weight-promoting effects of CPAP, these analyses were hampered by the substantial similarity in the populations recruited across trials (middle-aged, predominantly men with severe OSA). Thus, further research is needed to test for effect modification in important subpopulations. Nevertheless, the findings strongly confirm that CPAP therapy for OSA produces a small increase in weight and definitely does not lead to weight loss.

The cause of this weight gain is not yet clear. The reduction in leptin levels associated with CPAP therapy may result in increased hunger if the degree of leptin resistance does not change. Another explanation is that CPAP leads to reduced energy expenditure during sleep, ${ }^{10}$ as work of breathing is reduced due both to a patent upper airway as well as lung volumes rising to a more efficient point on the pressure-volume curve. Removal of the anorectic effects of hypoxia also may play an important role. ${ }^{11}$

Where the additional weight from CPAP goes is also not yet known. A number of trials have demonstrated no substantial impact of CPAP on visceral fat volume, ${ }^{12}$ although the imaging methods used may not be sensitive enough to exclude the small magnitude of weight gain observed. Improvements in growth hormone and insulin-like growth factor 1 signalling with CPAP might result in increased muscle mass. ${ }^{13}$ Further studies are clearly needed to determine whether CPAP-induced weight gain represents increases in fat, lean body or water compartments.

In understanding the impact of CPAP, it is important to note that increases in weight are also observed in overweight children with OSA following adenotonsillectomy, ${ }^{14}$ suggesting that weight gain is an effect of eliminating OSA rather than an effect specific to CPAP. Closer evaluation of the effects of other OSA therapies such as oral appliances would be helpful in establishing that the effect is not CPAP specific. Just as with CPAP, these data almost certainly already exist from prior RCTs and are ripe for meta-analysis.

Some readers may wonder if treatment recommendations for OSA should be altered in light of this identified adverse effect of CPAP therapy. The impact of $0.5 \mathrm{~kg}$ weight gain on health outcomes is fairly minimal and so should not change decision making regarding the use of CPAP in symptomatic OSA. However, it does give one pause regarding the use of CPAP in asymptomatic OSA where a cardiovascular benefit of CPAP has yet to be definitively established and makes more urgent the need for RCTs adequately powered to assess meaningful outcomes in this population.

These findings also highlight the need for the regular use of weight loss therapies in conjunction with CPAP in all overweight and obese patients with OSA. Although CPAP does not facilitate weight loss, it does not make weight loss strategies less effective either. The amount of weight loss achieved is no different in patients with OSA randomised to CPAP plus weight loss compared with weight loss alone. ${ }^{15}{ }^{16}$ In one small trial, the weight loss achieved with a dietary intervention was correlated to level of CPAP adherence suggesting that similar traits (eg, level of self-efficacy) predict the effectiveness of both interventions. ${ }^{17}$ 
Dietary intervention trials have demonstrated an improvement in both OSA severity and OSA-related symptoms with weight loss. ${ }^{18}$ However, some have argued that because weight regain is common with such lifestyle interventions, there may be little long-term benefit on OSA. In fact, several studies have now established that despite some weight regain, the improvements in OSA severity are durable. ${ }^{2021}$ Furthermore, a recent RCT demonstrated greater benefit in a wide range of cardiovascular risk factors obtained by combining CPAP with aggressive behavioural weight loss than CPAP alone. ${ }^{16}$ Thus, there is fairly strong evidence that intensive behavioural weight loss interventions are beneficial in overweight/obese patients with OSA. Implementation research is now sorely needed to determine how best to incorporate these lifestyle interventions into routine OSA care.

Further investigation into the role of pharmacological and surgical weight loss treatments in OSA management is another research priority. Although a recent trial found no additional benefit of gastric banding surgery over behavioural weight loss in OSA, ${ }^{22}$ more aggressive bariatric options such as gastric bypass or sleeve gastrectomy are clearly more effective at weight loss than gastric banding and probably more effective at treating OSA as well. ${ }^{23}{ }^{24}$ No RCTs have yet evaluated the efficacy of these procedures on OSA.

Despite the limitations in current knowledge, it is clear that clinicians need to pay more than lip service to weight loss counselling. Although practice guidelines on OSA treatment uniformly recommend weight loss be encouraged, ${ }^{25-27}$ clinicians need to do more than just encourage. The evidence base for intensive lifestyle interventions combining diet, activity and behavioural support in producing longterm weight loss and improved health outcomes is strong, ${ }^{28}$ but the tools are currently unfamiliar to most who treat OSA. Just as respiratory physicians treating COPD need to be adept with evidencebased methods for smoking cessation, those treating sleep apnoea need to be trained in best practices for achieving weight loss.

\section{Competing interests None.}

Provenance and peer review Commissioned;

internally peer reviewed.

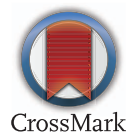

To cite Patel SR. Thorax 2015;70:205-206.

Published Online First 8 December 2014

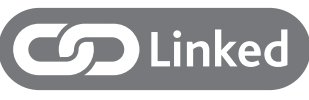

http://dx.doi.org/10.1136/thoraxjnl-2014-205361

Thorax 2015;70:205-206.

doi:10.1136/thoraxjn-2014-206484

\section{REFERENCES}

1 Young T, Peppard PE, Taheri S. Excess weight and sleep-disordered breathing. J Appl Physiol 2005;99:1592-9.

2 Newman $A B$, Foster $G$, Givelber $R$, et al. Progression and regression of sleep-disordered breathing with changes in weight: the Sleep Heart Health Study. Arch Intern Med 2005;165:2408-13.

3 Patel SR, Malhotra A, White DP, et al. Association between reduced sleep and weight gain in women. Am J Epidemiol 2006;164:947-54.

4 van den Berg JF, Knvistingh Neven A, Tulen $\mathrm{JH}$, et al. Actigraphic sleep duration and fragmentation are related to obesity in the elderly: the Rotterdam Study. Int I Obes (Lond) 2008;32:1083-90.

5 Phillips BG, Kato M, Narkiewicz K, et al. Increases in leptin levels, sympathetic drive, and weight gain in obstructive sleep apnea. Am J Physiol Heart Circ Physiol 2000;279:H234-7.

6 Ip MS, Lam KS, Ho C, et al. Serum leptin and vascular risk factors in obstructive sleep apnea. Chest 2000;118:580-6.

7 Loube DI, Loube AA, Erman MK. Continuous positive airway pressure treatment results in weight less in obese and overweight patients with obstructive sleep apnea. J Am Diet Assoc 1997;97: 896-7.

8 Quan SF, Budhiraja R, Clarke DP, et al. Impact of treatment with continuous positive airway pressure (CPAP) on weight in obstructive sleep apnea. I Clin Sleep Med 2013;9:989-3.

9 Drager LF, Brunoni AR, Jenner $R$, et al. Effects of continuous positive airway pressure on body weight in patients with obstructive sleep apnoea: a meta-analysis of randomized trials. Thorax 2015;70:258-64

10 Stenlof K, Grunstein R, Hedner J, et al. Energy expenditure in obstructive sleep apnea: effects of treatment with continuous positive airway pressure. Am J Physiol 1996;271(6 Pt 1):E1036-43.

11 Lippl FJ, Neubauer S, Schipfer S, et al. Hypobaric hypoxia causes body weight reduction in obese subjects. Obesity (Silver Spring) 2010;18:675-81.

12 Hoyos CM, Sullivan DR, Liu PY. Effect of CPAP on the metabolic syndrome: a randomised sham-controlled study. Thorax 2013;68:588-9.

13 Hoyos CM, Killick R, Keenan DM, et al. Continuous positive airway pressure increases pulsatile growth hormone secretion and circulating insulin-like growth factor-1 in a time-dependent manner in men with obstructive sleep apnea: a randomized sham-controlled study. Sleep 2014;37:733-41.

14 Katz ES, Moore RH, Rosen CL, et al. Growth after adenotonsillectomy for obstructive sleep apnea: an RCT. Pediatrics 2014;134:282-9.

15 Kajaste S, Brander PE, Telakivi T, et al. A cognitive-behavioral weight reduction program in the treatment of obstructive sleep apnea syndrome with or without initial nasal CPAP: a randomized study. Sleep Med 2004;5:125-31.

16 Chirinos JA, Gurubhagavatula I, Teff K, et al. CPAP, weight loss, or both for obstructive sleep apnea. N Engl J Med 2014;370:2265-75.

17 Hood MM, Corsica J, Cvengros J, et al. Impact of a brief dietary self-monitoring intervention on weight change and CPAP adherence in patients with obstructive sleep apnea. J Psychosom Res 2013;74:170-4.

18 Johansson $\mathrm{K}$, Neovius M, Lagerros YT, et al. Effect of a very low energy diet on moderate and severe obstructive sleep apnoea in obese men: a randomised controlled trial. BMJ 2009;339:b4609.

19 Tuomilehto HP, Seppa JM, Partinen MM, et al. Lifestyle intervention with weight reduction: first-line treatment in mild obstructive sleep apnea. Am J Respir Crit Care Med 2009;179:320-7.

20 Kuna ST, Reboussin DM, Borradaile KE, et al. Long-term effect of weight loss on obstructive sleep apnea severity in obese patients with type 2 diabetes. Sleep 2013;36:641-9A.

21 Tuomilehto H, Seppa J, Uusitupa M, et al. Weight reduction and increased physical activity to prevent the progression of obstructive sleep apnea: A 4-year observational postintervention follow-up of a randomized clinical trial. JAMA Intern Med 2013;173:929-30.

22 Dixon JB, Schachter LM, O'Brien PE, et al. Surgical vs conventional therapy for weight loss treatment of obstructive sleep apnea: a randomized controlled trial. JAMA 2012;308:1142-9.

23 Sjostrom L, Narbro K, Sjostrom CD, et al. Effects of bariatric surgery on mortality in Swedish obese subjects. N Engl J Med 2007;357:741-52.

24 Nagendran M, Carlin AM, Bacal D, et al. Self-reported remission of obstructive sleep apnea following bariatric surgery: cohort study. Surg Obes Relat Dis. Published Online First: 23 Oct 2014. doi:10.1016/i.soard.2014.10.011

25 Epstein LJ, Kristo D, Strollo PJ Jr, et al. Clinical guideline for the evaluation, management and long-term care of obstructive sleep apnea in adults. J Clin Sleep Med 2009;5:263-76.

26 Fleetham J, Ayas N, Bradley D, et al. Canadian Thoracic Society guidelines: diagnosis and treatment of sleep disordered breathing in adults. Can Respir J 2006; 13:387-92.

27 Scottish Intercollegiate Guidelines Network (SIGN). Management of Obstructive Sleep Apnoea/ Hypopnoea Syndrome in Adults. Edinburgh: SIGN; 2003. (SIGN publication no. 73). [cited 28 Oct 2014]. URL: http://www.sign.ac.uk

28 Jensen MD, Ryan DH, Apovian CM, et al. 2013 AHA/ACC/TOS guideline for the management of overweight and obesity in adults: a report of the American College of Cardiology/American Heart Association Task Force on Practice Guidelines and The Obesity Society. Circulation 2014;129: (25 Suppl 2):S102-38. 